\title{
sciendo
}

\section{CONTEXT BASED AND NON-CONTEXT BASED INTERPRETATION OF ENGLISH COMPOUNDS IN LEGAL DISCOURSE-A CASE STUDY WITH ESP LAW STUDENTS}

\author{
Jeta Hamzai \\ Language Center, South East European University, Tetovo, North Macedonia \\ jeta.rushidi@seeu.edu.mk
}

\begin{abstract}
Due to new innovations and changes, every language needs new words simply because there is a need for new words to name new things. It is a common occurrence for a speaker to use some words in a way that has never been used before in order to communicate directly about certain facts or ideas. When new inventions and changes come into people's lives, there is a need to name them and talk about them. If a new word is used by many speakers of the language, it will probably survive, and the same word will one day become an everyday word and enter the vocabulary of a language. This paper looks at compounding as one of the most productive word formation process in English. The term compounding refers to a process in which two or more lexemes are combined into one new word. When a word is formed by merging two or more words, each of which can be used separately, it is called a compound word. The term "word formation" has no universally accepted use. Word formation is sometimes defined as a process associated with changing the form of a word, for
\end{abstract}


example, affixation, which is, in fact, the subject of morphology. In a broader sense, word formation covers the processes of creating new lexical items. In English, word formation is of great importance because this phenomenon affects the English dictionary, which in addition to borrowing from various other languages is enriched in this way. The aim of this paper was to investigate the context based vs. non-context interpretation of English compounds by EFL students in legal discourse. The findings from the test run-questionnaire showed that students of English as a foreign language found it more difficult to apply compound words in context rather than choosing an appropriate definition for them, with or without a given context. Furthermore, students scored lower when $50 \%$ of the compounds were given in context.

Key words: word-formation, compounds, lexis, legal discourse, EFL

\section{INTRODUCTION}

Morphology as a linguistic discipline, which deals with the internal structure of word forms, can be divided into two main branches: lexical morphology (word formation) and inflectional morphology (grammar, conjugations/declensions) (Bauer, 1983) : 33). According to Bauer, word formation deals with the formation of new lexemes, while Yule (Yule, G., 2006:64) defines the processes (mechanisms) of word formation as "the study of the processes in which new words are created in a language." Such words enrich the vocabulary and thus create new lexemes.

Vocabulary is usually defined by form. This is not surprising given that the branch of linguistics that deals with the study of words is called morphology. According to McCarthy (1990), the word is defined as an independent linguistic element that carries some meaning, as opposed to all other dependent forms in language. Most of the words in English are created by combining morphemes, i.e. by adding prepositions and suffixes to certain basic words and roots. If language learners understand how such combining processes work, then they have the knowledge of the most important element needed to enrich the vocabulary (Anderson and Freebody,1981). In addition, studying the ways in which words are formed offers an important way of classifying words in teaching and learning.

Since the focus of this paper is investigating the interpretation of compounds, compounding can be examined closely. As a word-formation process, compounding involves combining two or more words in order to create a new unique form, which is very common in English. Some examples of compounds are skateboard, whitewash, superhighway, catlover, self-help, red-hot, textbook, fingerprint, sunburn, wallpaper, waterbed, etc. Thus, a 
compound, according to Bauer (1973), can be defined as a lexeme containing two or more stems, which subsequently have not participated in any derivation process.

The formation of compound words is a process of combining words to create a new word that "does not denote two things, but one", and "is pronounced as a whole", (Wisnicwski, 2007: 73). For example, award-winning (award + winning), helpline (help + line), input (in + put), long-running (long + running), postcard (post + card) are some examples of compound words. For Katamba (1993: 54) forming compound words is a very important way by which the English lexicon is enriched.

\section{PREVIOUS STUDIES}

Cutler (1983) and Corson (1985) emphasize the importance of word formation in language acquisition. Corson states that "People's difficulties in articulating and deciphering words in a given context are more often due to the form of the words than to their meaning" (Corson, 1985: 49). Moreover, most of the new words that students encounter in secondary education are morphologically derived from already known words (Aronoff, 1994).

Albanian and English are often contrasted in terms of word formation processes. Many studies have been conducted on the basis of contrastive analysis between English and Albanian, from a syntactic and morphological point of view. Scholars have also considered the methodological implications of teaching English lexicon as a foreign language. For example, authors such as Shqerra considered the role of derivation and the formation of compounds in the English language acquisition process and noted the following:

Because each language has its own characteristics, there are always differences between them, which make it difficult to learn foreign languages. In such cases, theory and practice should be seen as necessary for students. Also, special attention should be paid to the rules of derivation, (Shqerra, N. \& Shqerra, E., 2015: 117).

The research conducted by Kurani and Muho (2014) compares the plural forms of noun compounds in English and Albanian. From the information obtained it can be seen that the plural form of the compounds composed of two nouns in the Albanian language is formed by changing only the second noun, changing only the first noun, or without changing the singular form. However, most noun compounds in the English language have a basic chapter, to which they end, and the plural form is formed in the usual way. In addition, in compounds that have a single head that stands at the very beginning, the plural form is most often formed in that place. On the other hand, in compounds consisting of two chapters, one of which is already in the plural, the plural form is formed on the last element (Kurani \& Muho, 2014: $33)$. 
Sherko (2014) used two dictionaries as primary sources: The Dictionary of the Albanian Language Dictionary of Modern Albanian (1980), consisting of 41,000 words, and the English Dictionary Oxford Student's Dictionary student dictionary) consisting of 40,000 to 41,000 words. The main findings show that, statistically speaking, the number of compounds in the Albanian language is higher than that of the compounds in the English language. Specifically, $11.8 \%$ of the words in Albanian are compound, while in English only $4.48 \%$ of the words are compound.

Rushidi (2015) examined the similarities, differences, and identifications between the patterns for forming compounds in English and Albanian and analyzes the mistakes that students make when translating and classifying given compounds according to their constituent elements. The main findings of this research show that there are thirteen schemes for forming compounds in English and twelve in Albanian. Regarding the similarities, differences and identification between the compounds in English and Albanian, according to their form, it has been determined that similar patterns for forming compounds in English and Albanian are the following: noun + noun, adjective + noun, adverb + noun, noun + verb, verb + verb, adjective + verb, adverb + verb, noun + adjective, adjective + adjective, adjective + adjective, and adjective + adverb. On the other hand, differences according to the form are noticed in the following patterns for forming compounds: verb + noun, noun + adverb (there is no such case) and verb + adverb = noun. Accordingly, after considering the similarities and differences between the compounds in English and Albanian, in terms of their meaning, the following patterns for forming compounds are noted as similar in both languages: adjective + noun, adverb + noun and adverb + verb. Differences in meaning are noted in the following schemes for forming compounds: noun + noun, noun + verb, verb + verb, adjective + verb, noun + adjective and adjective + adjective. In the knowledge related to the most common mistakes made by English students as foreigners in classifying and translating compounds from English to Albanian, and vice versa, the following patterns for forming compounds were most common: noun + noun, verb + noun, verb + verb, adjective + verb, noun + adjective, adjective + verb, adverb + verb, adjective + adverb, adjective + noun, adverb + noun, noun + verb, adverb + adjective, noun + adverb, adverb + adverb. However, in terms of translation, the following compound formation patterns have often been mistranslated: noun + adjective, noun + adverb, adjective + verb, adverb + verb, adjective + noun, and verb + adverb $=$ noun. 
Gavrilovska (2001: 35) in her master's thesis entitled "Noun compounds in legal terminology in English", explores noun compounds in legal terminology, because among the three types of compounds (noun, adjective and verb) noun compounds are the most common as in the general language as well as in professional terminology. The noun compounds analyzed in this dissertation are of the following types:

1) Noun + noun (bench trial)

2) genitive of a noun + noun (court's order)3) adjective + noun (common law)

4) gerund / current participle + noun (threatening letter)

5) pass part + noun (suspended sentence)

6) infinitive + noun (break clause)

7) noun + adjective (Advocate General)

8) noun + gerund (lawmaking)

9) noun + past participle (case remanded)

10) noun + prepositional phrase (barrister-at-law)

11) nominalization of verb + particle (trade-in)

The morphological classification of the examples representing the noun compounds from the legal register is performed based on the type of word to which the given members of the compound belong. Because in two-syllable compounds one member is a noun and the other member of the compound can be: noun, verb, adjective, present or past participle or particle, the noun compounds from the legal register are grouped into the above eleven groups (Gavrilovska, 2001: 114).

Based on the examples obtained from the corpus of compounds with legal terminology, it was concluded that most of the found compounds (approximately 50\%) are compounds that belong to the subgroup noun + noun; in terms of representation it is followed by other subgroups according to the following disposition, which represents their representation in the corpus analyzed:

1. noun + noun

2. adjective + noun

3. noun + prepositional phrase 


\section{4. gerund / current participle + noun}

5. noun + gerund, etc.

The following subgroups are distinguished as examples of compounds that are least productive: nominalization of verb + particle, adjective + gerund, and preposition + noun (2011: 115). As a result of the overall research of noun compounds in the legal register, Gavrilovska came to the conclusion that noun compounds, as well as compounds in general, represent a special part of the field of word formation, both in general and in professional language. Therefore, she argues that it is necessary to pay more attention to the word formation processes in professional textbooks and in sentences. In professional textbooks, for example, the process of forming compounds in English should be processed through appropriate texts and grammar exercises, and in professional dictionaries to enter as many compounds as possible (as well as the appropriate forms for their formation). The above will contribute to the development of better professional textbooks and dictionaries and of course to the improvement of teaching in English, which will be in function of the given professional field (2001: 116). The process of forming complex words today is an important way of forming new words in English. Several authors - as well as the fact of the increasing number of words that have become an integral part of the standard English lexicon-support this claim. When it comes to the productivity of different types of compounds, one can rightly expect that certain types of compounds will continue to be more productive than others because many English compound words are formed by combining nouns with other parts of speech.

\section{PRESENT STUDY Research Questions}

This paper aims to answer the following research questions:

1. What is the context-based interpretation of English compounds (noun, verb, adjective, and adverb compounds) by EFL students in legal discourse?

2. What is non-context-based interpretation of English compounds (noun, verb, adjective, and adverb compounds) by EFL students in legal discourse?

\section{Participants}

The participants involved in this study were 75 students studying at South East European University in Tetovo and Skopje, Macedonia. These 75 Law students were from the first, 
second and third year attending the following courses: Academic English, Advanced Academic English, and English for Specific Purposes 1\& 2 (ESP Law 1 \& 2).

\section{Instruments}

The instrument used for the data collection was an online test run questionnaire. In the first part, students were given multiple choice questions. They were given three possible answers for each compound word, with only one option to be selected. In this part, students interpreted the meaning of English compounds in the field of law.

In the second part of the test run questionnaire, students were asked multiple choice questions. Students were given three possible answers for each compound word, with only one option to be selected. This section had a context. The three possible answers and the context for each question were borrowed from the Webster online dictionary http://www.merriam-webster.com/ and online articles.

In the third part of the test run questionnaire, students were asked to write 26 sentences using the 26 compounds provided. Throughout the three parts of the test run questionnaire the following 26 compounds with the given patterns were included:

1) LAWSUIT (noun +noun)

2) MANSLAUGHTER (noun +noun)

3) HUNG JURY (verb + noun)

4) SEARCH WARRANT (verb + noun)

5) ADVERSE WITNESS (adjective + noun)

6) LEGAL CUSTODY (adjective + noun)

7) OVERCOMPENSATION (adverb + noun)

8) BYSTANDER (adverb + noun)

9) PROOFREAD (noun + verb)

10) EXCHANGE (noun + verb)

11) COUNTERSIGN (verb + verb)

12) CROSS-CHECK (verb + verb)

13) BLACKMAIL (adjective + verb)

14) UPHOLD (adjective + verb)

15) OUTLINE (adverb + verb)

16) OVERSEE (adverb + verb) 
17) STEADFAST (noun + adjective)

18) TRUSTWORTHY (noun + adjective)

19) FULL-BLOWN (adjective+ adjective)

20) LEGALLY BINDING (adjective+ adjective)

21) OVERQUALIFIED (adverb + adjective)

22) OVERCOMPENSATORY (adverb + adjective)

23) WHEREBY (adverb+ adverb)

24) HEREIN (adverb+ adverb)

25) PUSHOVER (verb + adverb = noun)

26) WALKOUT $($ verb + adverb = noun $)$

\section{DISCUSSION ON THE FINDINGS}

\section{Findings from the demographic data from the first part of the questionnaire}

The participants in the research were seventy-five students, $60 \%$ of whom were aged between $18-20 ; 37.3 \%$ aged between $21-23$; and $2 \%$ were aged $24-26$ years old. $42.7 \%$ of the participants were females and 57.3\% were males. Most of the participants (60\%) were attending the fourth semester of their studies; $24 \%$ were attending the sixth semester, while $10.7 \%$ were in the second semester. The smallest numbers of the participants $(5.3 \%)$ were attending the third semester of their studies. The mother tongue of most of the participants (85.3\%) was Albanian, while Macedonian was the mother tongue of $12 \%$ of the participants. Additionally, Turkish was the mother tongue of $2.7 \%$ of survey participants. Regarding the completed levels of the English Language Program for Basic Skills of the Language Center, the data collected show that $69.3 \%$ of the participants completed three levels, while $22.7 \%$ completed two. $8 \%$ of the participants had completed only one level of the program. The results related to the last question of the questionnaire intended for demographic data show that $74.7 \%$ of the participants took/attended the course Legal English 2. Legal English 1 was attended by $12 \%$ of the participants. A small number of participants $(8 \%)$ attended Advanced Academic English, while 5.3\% attended Academic English.

\section{Findings from the first and second part of the test questionnaire for students}

This part of the research compares the way EFL students interpret the compounds in Legal English with and without a given context. The comparative analysis of how the same students answer the 52 questions from the test questionnaire is shown in percentage in Table 
1. In the first and second part of the test run questionnaire, all 75 students answered all the questions and the results are illustrated below:

\begin{tabular}{|c|c|c|}
\hline Compound words & $\begin{array}{l}\text { Part } 1 . \\
\text { Context-based } \\
\text { interpretation }\end{array}$ & $\begin{array}{l}\text { Part } 2 . \\
\text { Non-context- } \\
\text { based } \\
\text { interpretation }\end{array}$ \\
\hline 1.LAWSUIT (noun + noun) & $65 \%$ & $66 \%$ \\
\hline 2.MANSLAUGHTER (noun +noun) & $82 \%$ & $91 \%$ \\
\hline 3.HUNG JURY (verb + noun) & $58 \%$ & $68 \%$ \\
\hline 4.SEARCH WARRANT (verb + noun) & $73 \%$ & $65 \%$ \\
\hline $\begin{array}{l}\text { 5.ADVERSE WITNESS } \\
\text { (adjective + noun) }\end{array}$ & $67 \%$ & $68 \%$ \\
\hline 6.LEGAL CUSTODY (adjective + noun) & $56 \%$ & $60 \%$ \\
\hline 7.OVERCOMPENSATION (adverb + noun) & $19 \%$ & $24 \%$ \\
\hline 8. BYSTANDER (adverb + noun) & $81 \%$ & $81 \%$ \\
\hline 9. PROOFREAD (noun + verb) & $64 \%$ & $66 \%$ \\
\hline 10. EXCHANGE (noun + verb) & $94 \%$ & $80 \%$ \\
\hline 11. COUNTERSIGN (verb + verb) & $73 \%$ & $81 \%$ \\
\hline 12. CROSS-CHECK (verb + verb) & $63 \%$ & $74 \%$ \\
\hline 13. BLACKMAIL (adjective + verb) & $74 \%$ & $81 \%$ \\
\hline 14. UPHOLD (adjective + verb) & $74 \%$ & $71 \%$ \\
\hline 15. OUTLINE (adverb + verb) & $68 \%$ & $62 \%$ \\
\hline 16. OVERSEE (adverb + verb) & $69 \%$ & $54 \%$ \\
\hline 17. STEADFAST (noun + adjective) & $72 \%$ & $77 \%$ \\
\hline 18. TRUSTWORTHY (noun + adjective) & $87 \%$ & $81 \%$ \\
\hline 19. FULL-BLOWN (adjective+ adjective) & $81 \%$ & $72 \%$ \\
\hline 20. LEGALLY BINDING (adjective+ adjective) & $60 \%$ & $63 \%$ \\
\hline 21.OVERQUALIFIED (adverb + adjective) & $82 \%$ & $76 \%$ \\
\hline 22.OVERCOMPENSATORY (adverb + adjective) & $65 \%$ & $68 \%$ \\
\hline 23. WHEREBY (adverb+ adverb) & $58 \%$ & $56 \%$ \\
\hline 24. HEREIN (adverb+ adverb) & $67 \%$ & $57 \%$ \\
\hline 25. PUSHOVER $($ verb + adverb $=$ noun $)$ & $67 \%$ & $71 \%$ \\
\hline 26. WALKOUT (verb + adverb = noun) & $82 \%$ & $76 \%$ \\
\hline
\end{tabular}

Table 1. Context based interpretation vs. non context interpretation of compounds

\section{Noun compounds}

Questions 1-8, 25 and 26 in both parts of the test run questionnaire (as shown in Table 1) examined whether students could guess the meaning of the noun compounds and special noun compounds with and without a given context. Results show that in terms of context based and non-context-based interpretation students scored higher when interpreting the 
meaning of the noun compound MANSLAUGHTER (noun +noun) whereas they scored lower when interpreting the noun compound OVERCOMPENSATION (adverb + noun).

\section{Verb compounds}

The findings from questions 9-16 show that in terms of context based and non-context based interpretation students scored higher when interpreting the meaning of the verb compound EXCHANGE (noun + verb) whereas they scored lower when interpreting the verb compound CROSS-CHECK (verb + verb) in context and the verb compound OVERSEE (adverb + verb) when context was not provided.

\section{Adjective compounds}

Results from questions 17-22 show that students scored better results in interpreting the adjective compound TRUSTWORTHY (noun + adjective) with and without context whereas they scored lower results when interpreting the adjective compound OVERCOMPENSATORY (adverb +adjective) in both parts of the questionnaire.

\section{Adverb compounds}

Findings from questions 22 and 23 show that students scored higher results when interpreting the adverb compound HEREIN (adverb+ adverb) with and without context whereas they scored lower results when interpreting the adjective compound WHEREBY (adverb+ adverb) in both parts of the questionnaire.

\section{Findings from the third part of the student test run questionnaire}

In this part of the questionnaire, the participants were asked to compose twenty-six sentences that included twenty-six given compounds. The same twenty-six compounds were used in the first two parts of the test questionnaire. The results show (see Table 2) that only fifty-three out of seventy-five students composed sentences containing the twenty-six given compounds. So, the number of students who actually answered is 53. The percentage of answers by students is 70.66 . 


\begin{tabular}{|l|l|l|}
\hline & $\begin{array}{l}\text { Using compounds } \\
\text { in the correct } \\
\text { context (sentences) }\end{array}$ & $\begin{array}{l}\text { Giving a definition } \\
\text { for the given } \\
\text { compounds }\end{array}$ \\
\hline 1.LAWSUIT (noun + noun) & $32.07 \%$ & $49.05 \%$ \\
\hline 2.MANSLAUGHTER (noun +noun) & $33.96 \%$ & $52.83 \%$ \\
\hline 3.HUNG JURY (verb + noun) & $32.07 \%$ & $52.83 \%$ \\
\hline 4.SEARCH WARRANT (verb + noun) & $28.30 \%$ & $43.39 \%$ \\
\hline 5.ADVERSE WITNESS (adjective + noun) & $24.52 \%$ & $50.94 \%$ \\
\hline 6.LEGAL CUSTODY (adjective + noun) & $39.60 \%$ & $26.41 \%$ \\
\hline 7.OVERCOMPENSATION (adverb + noun) & $5.66 \%$ & $39.62 \%$ \\
\hline 8. BYSTANDER (adverb + noun) & $33.96 \%$ & $64.15 \%$ \\
\hline 9. PROOFREAD (noun + verb) & $32.07 \%$ & $49.05 \%$ \\
\hline 10. EXCHANGE (noun + verb) & $35.84 \%$ & $32.00 \%$ \\
\hline 11. COUNTERSIGN (verb + verb) & $22.64 \%$ & $49.05 \%$ \\
\hline 12. CROSS-CHECK (verb + verb) & $33.96 \%$ & $54.71 \%$ \\
\hline 13. BLACKMAIL (adjective + verb) & $32.07 \%$ & $58.49 \%$ \\
\hline 14. UPHOLD (adjective + verb) & $11.32 \%$ & $43.39 \%$ \\
\hline 15. OUTLINE (adverb + verb) & $32.07 \%$ & $45.28 \%$ \\
\hline 16. OVERSEE (adverb + verb) & $26.41 \%$ & $56.60 \%$ \\
\hline 17. STEADFAST (noun + adjective) & $33.96 \%$ & $47.16 \%$ \\
\hline 18. TRUSTWORTHY (noun + adjective) & $39.62 \%$ & $52.83 \%$ \\
\hline 19. FULL-BLOWN (adjective+ adjective) & $33.96 \%$ & $49.05 \%$ \\
\hline 20. LEGALLY BINDING (adjective+ adjective) & $37.73 \%$ & $43.39 \%$ \\
\hline 21.OVERQUALIFIED (adverb + adjective) & $33.96 \%$ & $52.83 \%$ \\
\hline 22.OVERCOMPENSATORY (adverb + adjective) & $39.62 \%$ & $30.18 \%$ \\
\hline 23. WHEREBY (adverb+ adverb) & $33.96 \%$ & $30.18 \%$ \\
\hline 24. HEREIN (adverb+ adverb) & $33.96 \%$ & $52.83 \%$ \\
\hline 25. PUSHOVER (verb + adverb = noun) & $28.30 \%$ & $24.52 \%$ \\
\hline 26. WALKOUT (verb + adverb = noun) & $15.09 \%$ & $49.05 \%$ \\
\hline & & \\
\hline
\end{tabular}

Table 2. The use of compounds in the correct context vs. giving definitions for the same

It is important to mention that students answered the last part of the questionnaire in different ways. Some of the students used the compounds in the correct context, and some of the students wrote a definition of the given compounds, although this was not stated in the instructions of the questionnaire. In addition, some of the students wrote an inappropriate definition of the given compounds. Also, some of the students made mistakes regarding using the given compounds in an inappropriate context or using an inappropriate form of the words themselves. 
From the first column of Table 2 (Using compounds in the correct context - sentences), which refers to the third part of the questionnaire, it can be noticed that the percentage of correct answers, in terms of writing sentences that will contain the listed compounds, varies between $5.66 \%$ and $39.62 \%$. Therefore, the average percentage of correct answers is $30.26 \%$, which is significantly less than that of the first and second part of the questionnaire.

The second column (Giving a definition for the given compounds) shows the percentage of the correct definitions given for the twenty-six compounds by the students, which varies from $24.52 \%$ to $64.15 \%$. Therefore, the average percentage of correct answers is $46.15 \%$, which is much higher than the part of the questionnaire that refers to writing sentences that contain the same compounds. Although according to the instructions (in the third part of the questionnaire), students were asked to write sentences with the given compounds, many of them wrote definitions for them. This means that the students did not have enough self-confidence to give context, because not all of them internalized the twentysix vocabulary terms and therefore it was easier for them to define them. Most of the spelled definitions are quite similar to those already listed in the first and second part of the questionnaire. Although they had already encountered the compounds in a given context, it was difficult for the students to use them in a new one.

\section{CONCLUSION}

In order to better understand the complexity of teaching and learning compounds in English as a foreign language, a research methodology was developed to examine the ways in which students interpreted compounds with and without a given context.

The findings suggest that EFL students must first meet new vocabulary concepts in context and the ways in which they are formed and used. Then, it is logical that students can be given the opportunity to try to recognize the terms in context, in terms of their form and use. A suggestion that would alleviate methodological difficulties in teaching and testing students' knowledge of compounds would be to consider Bloom's taxonomy. Also, according to authors such as Graves (2006), Kieffer and Lesaux, (2012a / 2012b), it is crucial to enable students to gain morphological awareness and help them recognize and manipulate new words. Logically, students who recognize how words are formed in English, by combining affixes and roots, have more words and understand texts better than others (Kieffer and DiFelice Box, 2013). Morphological awareness refers to students' awareness of the morphological structure of words and their ability to think and change them. In other words, 
it signifies students' understanding of the structure of words as combinations of the smallest meaning elements called morphemes, to the formation of different types of compounds.

The relevance of this paper lays in the importance of word formation rules. Since word formation is one of the most effective ways to expand any vocabulary and has great importance in determining the meaning of words, research methods used such as: selective, morphological, and comparative were conducted. 


\section{REFERENCES}

1. Anderson, R., C., Freebody, P. (1981). Vocabulary knowledge. In J. Guthrie (Ed.), Comprehension and teaching: Research reviews, pp, 77-117. Newark, DE: International Reading Association.

2. Aronoff, M. (1976). Word Formation in Generative Grammar. Cambridge: MIT Press.

3. Bauer, L. (1973). English word-formation. Cambridge: Cambridge University Press, London, UK.

4. Corson, D. (1985). The Lexical Bar. Oxford: Pergamon Press.

5. Cutler, A. (1983). Degree of transparency in word formation. In "Canadian Journal of Linguistics", 26, pp. 40-55.

6. Гаврилоска, С. (2001). Именски сложенки во правната терминологија на англискиот јазик. Скопје: необјавен магистерски труд.

7. Katamba, F. (1993). Morphology. London: Macmillan.

8. Kurani, A. \& Muho, A. (2014). A morphological comparative study between Albanian and English language. European Scientific Journal.

9. McCarthy, M. (1990). Vocabulary. Oxford University Press: Oxford.

10. Rushidi, J. (2015). Contrastive analysis of English compounds and their correspondents in Albanian language. Journal of Foreign Language Teaching and Applied Linguistics, 1 (3). ISSN 2303-5528 Retreived on 25.10.2016 from http://eprints.ibu.edu.ba/2892/

11. Shqerra, N., \& Shqerra, E. (2015). The Role of Derivation and Compounding in the Process of English Language Acquisition. Journal of Educational and Social Research MCSER Publishing, Rome-Italy Vol. 4 No. 2 April 2014, p.117.

12. Wisniewski, K. (2007). Word Formation. Tlumaczenia Angielski. http://www.tlumaczeniaangielski.info/linguistics/word-formation.htm, retrieved 07.02.2015.

13. Yule, G. (2006).The study of language. (2nd ed). UK: Cambridge University Press. 